\title{
Evolución del conocimiento sobre la pungencia de la cebolla (Allium cepa L.) y del pimiento (Capsicum spp.): desde sus orígenes hasta el potencial nutracéutico actual. Revisión bibliográfica
}

\author{
O. Fayos, C. Mallor y A. Garcés-Claver*
}

Centro de Investigación y Tecnología Agroalimentaria de Aragón. Departamento de Hortofruticultura. Instituto Agroalimentario de Aragón - IA2 (CITA-Universidad de Zaragoza), Avda. Montañana 930, 50059, Zaragoza, España

\section{Resumen}

La cebolla (Allium cepa L.) y el pimiento (Capsicum spp.) han sido cultivados durante miles de años por sus propiedades medicinales y terapéuticas. En la actualidad, estas propiedades bioactivas promotoras de la salud se han atribuido, principalmente, a la acción de los compuestos responsables de la pungencia de la cebolla y del pimiento. El potencial nutracéutico de los sulfóxidos de cisteína en cebolla y de los capsinoides y capsicinoides en pimiento ha despertado especial interés en las industrias tanto farmacéuticas como agroalimentarias para el desarrollo de nuevos alimentos funcionales. Además, el aumento de la demanda por los consumidores de alimentos frescos más saludables ha incentivado el desarrollo de nuevos programas de mejora de la calidad dirigidos a la obtención de variedades hortícolas con mayores contenidos en estos compuestos nutracéuticos. La presente revisión aborda estos aspectos desde el punto de vista de la complejidad de las rutas de biosíntesis de los compuestos y cómo las técnicas analíticas modernas, más precisas y sensibles, se han convertido en una herramienta fundamental para el estudio del carácter picante.

Palabras clave: Sulfóxidos de cisteína, capsinoides, capsicinoides, alimentos funcionales, rutas de biosíntesis, HPLC.

\section{Abstract \\ Evolution of the pungency of onion (Allium cepa L.) and pepper (Capsicum spp.) from its origin to the current nutraceutical potential}

Onion (Allium cepa L.) and pepper (Capsicum spp.) have been cultivated for thousands of years due to their medicinal and therapeutic properties. Nowadays, these health-promoting properties have been attributed to the bioactive compounds responsible for the pungency of onion and pepper. The nutraceutical potential showed by cysteine sulfoxides in onion and by capsinoids and capsaicinoids in pepper has given rise to a special interest in the pharmaceutical and food industries for the development of novel functional foods. In addition, the increase in demand for consumers of healthy fresh foods has stimulated the development of breeding programs for obtaining new vegetable varieties with higher contents of nutraceutical compounds. The present review addresses these aspects from the point of view of the complexity of the biosynthesis pathways of such compounds, and as modern analytical techniques, more precise and sensitive, have become a fundamental tool for the study of the pungency.

Keywords: S-alk(en)yl-L-cysteine sulfoxides, capsinoids, capsaicinoids, functional foods, biosynthesis pathways, HPLC.

\footnotetext{
* Autor para correspondencia: agarces@cita-aragon.es
} https://doi.org/10.12706/itea.2018.007 


\section{Introducción}

La cebolla (Allium cepa L.) y el pimiento (Capsicum spp.) han sido cultivados durante miles de años, tanto por su valor como especia o alimento como por sus propiedades profilácticas y terapéuticas. En la actualidad, gran parte de estas propiedades medicinales se han atribuido a la acción de los compuestos responsables de la pungencia (picor) de la cebolla, los sulfóxidos de cisteína (SCs), y del pimiento, los capsinoides y capsicinoides (CTOs/ (APs). Estos compuestos son considerados nutracéuticos por su bioactividad antioxidante, antinflamatoria, analgésica, antiasmática, antimicrobiana, antiplaquetaria, antitrombótica, antiobesidad, hipocolesterolemiante, hipolipemiante e hipoglucemiante (Rose et al., 2005; Corzo-Martínez et al., 2007; Luo et al., 2011), convirtiéndose en compuestos de gran interés para las industrias tanto farmacéuticas como agroalimentarias enfocadas al desarrollo de nuevos alimentos funcionales. Además, la creciente demanda de alimentos frescos más saludables ha incentivado el desarrollo de programas de mejora de la calidad de la cebolla y del pimiento con el objeto de obtener nuevas variedades con mayores contenidos en estos compuestos. El desarrollo de técnicas analíticas, cada vez más precisas, mejora la eficiencia del criterio de selección en dichos programas y contribuyen, junto con las herramientas de la genómica y la proteómica, al esclarecimiento de las rutas de biosíntesis y de los genes implicados en la pungencia de ambos cultivos. Estos aspectos se abordan en la presente revisión.

\section{Compuestos responsables del picor}

Los SCs y CTOs/CAPs son compuestos estructuralmente muy diferentes pero comparten una característica en común: la pungencia. Ambos grupos de compuestos son capaces de activar los receptores neuronales TRPV1 (re- ceptor potencial transitorio vainilloide tipo 1) provocando las sensaciones de picor, calor o incluso dolor.

\section{Sulfóxidos de cisteína: precursores del aroma, sabor y picor de la cebolla}

En cebolla, el contenido en compuestos azufrados puede alcanzar hasta el $5 \%$ de su peso seco. La mayoría de estos compuestos se encuentran en forma de aminoácidos no proteicos, como los SCs (Lancaster y Shaw, 1989). Los SCs son los precursores no aromáticos de una amalgama de compuestos azufrados volátiles, inestables y altamente reactivos responsables de gran variedad de aromas y sabores y de la pungencia de los Alliums y de algunas brásicas (Thomas y Parkin, 1994; Kubec y Dadákova, 2008).

Los trabajos de Stoll y Seebeck (1947) fueron pioneros en el análisis de los (SCS) al identificar la aliina (sulfóxido de S-alil-L-cisteína; ASC) en ajo ( $A$. sativum). Una década más tarde se identificaron en cebolla ( $A$. cepa) otros tres SCs: la isoaliina (sulfóxido de trans-(+)-S(1-propenil)-L-cisteína; 1-PeSC), la metiina (sulfóxido de S-metil-L-cisteína; MeSC) y la propiina (sulfóxido de S-propil cisteína, PSC) (Virtanen y Matikkala, 1959; Matikkala y Virtanen, 1967). Posteriormente, el desarrollo de técnicas analíticas más sensibles y precisas facilitó la determinación de otros SCs minoritarios como la etiina (sulfóxido de S-etil-Lcisteína, ESC) en cebolla y ajo entre otras especies de Allium (Kubec et al., 1999; Kubec et al., 2000), la butiina (sulfóxido de $S$-n-butil-Lcisteína, BSC) en bulbos de $A$. siculum (Kubec et al., 2002) y el sulfóxido de $S$-(3-pentenil)-Lcisteína en semillas de cebolla de la variedad local 'tropeana' (Dini et al., 2008). Recientemente, los sulfóxidos $S$-(3-pirrolil)-L-cisteína y S-(2-piridil)-L-cisteína se han identificado en bulbos de algunas especies de Allium pertenecientes al subgénero Melanocrommyum (Jedelská et al., 2008; Kusterer et al., 2010). 
La hidrólisis de los SCs por acción de la enzima alinasa, (S-alqu(en)il-L-cisteina sulfóxido liasa; EC 4.4.1.4), desencadena una serie de reacciones originando gran variedad de compuestos azufrados aromáticos (Schwimmer y Mazelis, 1963) (Figura 1). En tejidos vegetales intactos, la alinasa se confina en las vacuolas celulares mientras que los SCs se encuentran en el citoplasma. Cuando la estructura celular se rompe al cortar, masticar o cocinar el tejido, se produce la hidrólisis de los SCs [RSO- $\left.\mathrm{CH}_{2}-\mathrm{CH}\left(\mathrm{NH}_{2}\right) \mathrm{COOH}\right]$, donde $-\mathrm{R}$ representa

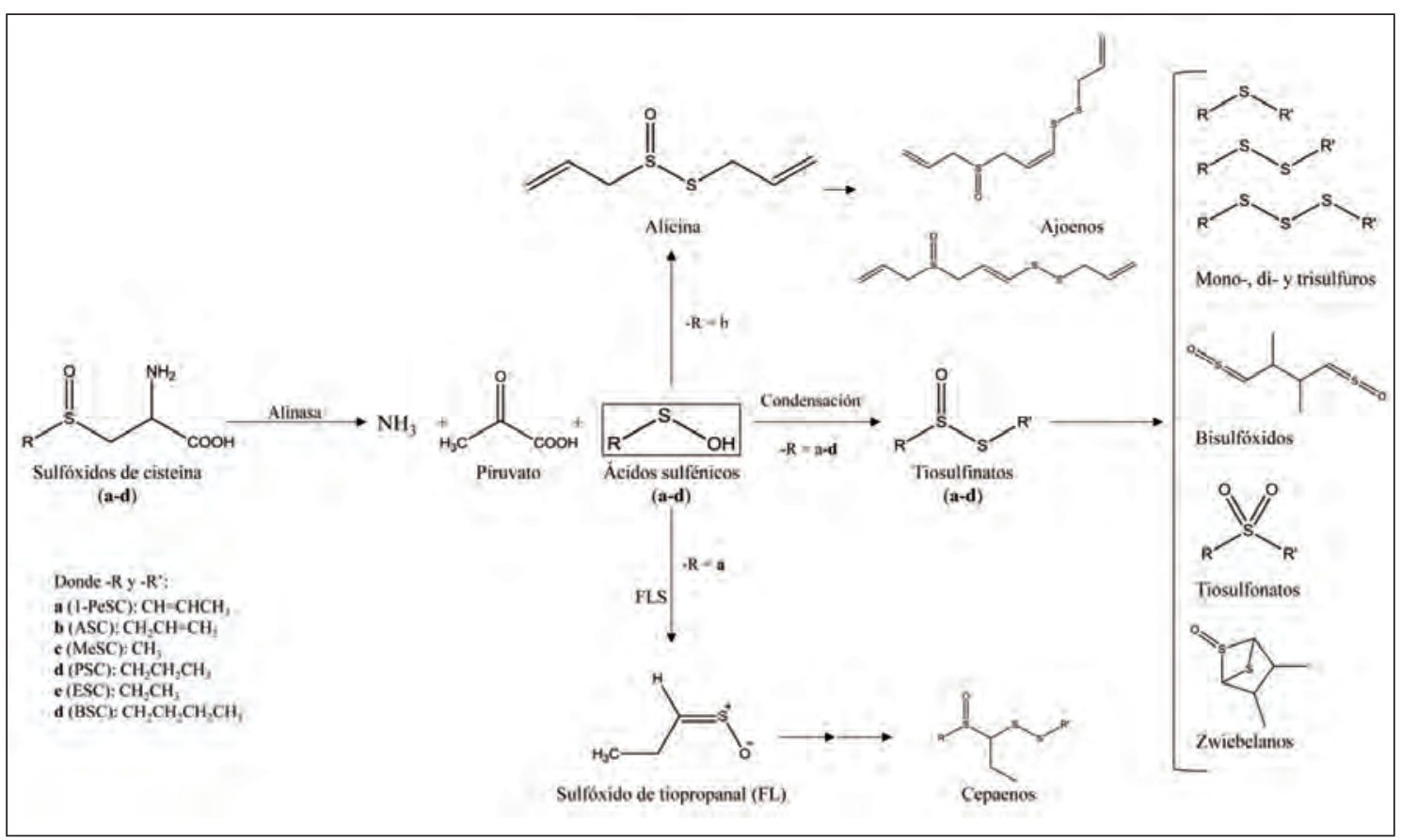

Figura 1. Reacciones químicas y compuestos generados a partir de la hidrólisis enzimática de los sulfóxidos de cisteína (modificado a partir de las rutas propuestas por Block et al., 1996;

Rose et al., 2005; Corzo-Martínez et al., 2007 y Block, 2013).

Figure 1. Chemical reactions and compounds generated from enzymatic hydrolysis of cysteine sulfoxides (modified from Block et al., 1996; Rose et al., 2005;

Corzo-Martínez et al., 2007; Block, 2013).

los grupos $\mathrm{CH}_{3}-(\mathrm{MeSC}) ; \mathrm{CH}_{3}-\mathrm{CH}_{2}-\mathrm{CH}_{2}-(\mathrm{PSC})$; $\mathrm{CH}_{3}-\mathrm{CH}=\mathrm{CH}-(1-\mathrm{PeSC})$ y $\mathrm{CH}_{2}=\mathrm{CH}-\mathrm{CH}-(\mathrm{ASC})$, originándose, en primer lugar piruvato, amoniaco y ácidos sulfénicos (Lancaster y Collin, 1981). Estos ácidos sulfénicos (R-S-OH), son compuestos volátiles altamente reactivos por lo que rápidamente se reorganizan y condensan en forma de tiosulfinatos (R-S-SO-R'). La heterogénea mezcla de tiosulfinatos resul- tante es consecuencia de la naturaleza de los grupos - $R$ y $-R^{\prime}$ de sus precursores y la proporción en la que se encuentren en la mezcla, determinará los aromas primarios, característicos de las distintas especies de Allium. A su vez, los tiosulfinatos son compuestos volátiles muy inestables por lo que rápidamente reaccionan entre ellos o con otros ácidos sulfénicos originando formas más estables como los tio- 
sulfonatos ( $\left(\mathrm{R}-\mathrm{SO}_{2}-\mathrm{S}-\mathrm{R}^{\prime}\right)$; monosulfuros $\left(\mathrm{R}-\mathrm{S}-\mathrm{R}^{\prime}\right)$; disulfuros (R-S-S-R'); trisulfuros (R-S-S-S-R') y otros tiosulfinatos (Block et al., 1996; Rose et al., 2005; Corzo-Martínez et al., 2007; Block, 2013).

La isoaliina (1-PeSC): precursor del factor lacrimógeno

En líneas generales, podemos considerar que en cebolla el SCs mayoritario es la 1-PeSC seguidamente de la MeSC y algo de PSC, aunque también se ha determinado ASC en algunas variedades (Edwards et al., 1994). En consecuencia, el ácido sulfénico mayoritario derivado de la 1-PeSC, por acción de la alinasa, es el ácido 1-propenesulfénico. Este ácido sulfénico se convierte en sulfóxido de tiopropanal, también conocido como factor lacrimógeno, por acción de una segunda enzima llamada sintasa factor lacrimógeno (FLS; EC 5.3.---). Este factor es el responsable de la irritación y el lagrimeo ocular originados al cortar la cebolla (Imai et al., 2002).

\section{Otros compuestos azufrados de interés}

A partir de la hidrólisis enzimática de la 1-PeSC se origina el factor lacrimógeno así como una pequeña proporción de tiosulfinatos, entre los que se incluyen los cepaenos, originados de forma no enzimática debido a la inestabilidad del ácido 1-propenesulfénico (Imai et al., 2002). Por otro lado, la hidrólisis de la ASC da lugar a la alicina (S-alil-2-propentiosulfinato), originada por la condensación del ácido 2-propenesulfénico. La alicina es muy inestable por lo que reacciona con ella misma para formar sulfuros, trisulfuros y tiosulfonatos como los ajoenos. Cepaenos y ajoenos son estructuralmente muy parecidos y ambos grupos de compuestos son de gran interés en el ámbito médico. Simultáneamente, los ácidos sulfénicos, derivados de la degradación de todos los SCs, originan una mezcla de tiosulfinatos, bisulfóxidos y zwiebelanos, entre otros (Block et al., 1996; Rose et al., 2005; Corzo-Martínez et al., 2007; Block, 2013).
Otros compuestos azufrados de gran interés son los $\gamma$-glutamil péptidos ( $\gamma$ GPs), que si bien no contribuyen directamente con el aroma, sabor y picor, actúan como reserva de nitrógeno y azufre durante la dormancia de los bulbos y como intermediarios en la ruta de biosíntesis de los SCs (Lancaster y Shaw, 1989).

La síntesis de unos compuestos azufrados en lugar de otros y la proporción en la que se encuentran están influenciadas por las características genéticas de la planta y las condiciones ambientales en las que crece y se desarrolla. La formación de unos compuestos $u$ otros es el factor determinante para el desarrollo de unos determinados aromas y sabores característicos de cada especie, así como de las diferentes actividades biológicas (Yoo y Pike, 1998).

\section{Capsinoides y capsicinoides (CTOs/CAPs) responsables del picor en Capsicum}

Los capsinoides y capsicinoides (CTOs/CAPs) son exclusivos del género Capsicum y si bien no contribuyen en su valor nutritivo, son los causantes del picor y calor característico del pimiento al ser consumido. Los capsicinoides (CAPs) han sido objeto de estudio desde principios del siglo XIX, sin embargo, la estructura química de la capsicina [(E)-N-[(4- hidroxi3-metoxifenil)metil]-8-metil-6-nonanamida; Cap] no se determinó hasta 1919 (Nelson, 1919). La Cap y la dihidrocapsicina [N-(4-hidroxi-3-metoxibenzil)-8-metilnonanamida; dhCap] son los mayoritarios, representando hasta el $90 \%$ del contenido total de CAPs (Aza-González et al., 2011). Aunque Cap, dhCap y nordihidrocapsicina [N-(4- hidroxi-3metoxibenzil)-7-metiloctanamida; ndhCap] son los tres CAPs más frecuentes, en la actualidad se han descrito, en frutos de pimiento, más de 20 análogos a la Cap (Bosland y Votava, 2012).

El descubrimiento de los capsinoides fue posterior; Yazawa et al. (1989) identificaron en los 
frutos del cultivar 'CH19-Sweet' (C. annuum) un grupo de compuestos análogo a los CAPs a los que llamaron capsaicinoid-like substances (CLSs). Años más tarde Kobata et al. (1998) establecieron la estructura química de los CLSs y los renombraron como capsinoides (CTOs). Hasta la fecha se han descrito tres CTOs naturales, capsiato (4-hidroxi-3-metoxibenzil (E)-8metil-6-nonanoato; Cto), dihidrocapsiato (4hidroxi-3-metoxibenzil 8-metilnonanoato; dhCto) y nordihidrocapsiato (4-hidroxi-3-metoxibenzil 7-metiloctanoato; ndh(to), siendo los dos primeros los mayoritarios. No obstante, al igual que ocurre con los CAPs, podrían existir otros CTOs minoritarios.

\section{Diferencias entre capsinoides (CTOs) $y$ capsicinoides (CAPs)}

Los CAPs se forman por la condensación de un anillo de vanillilamina, común a todos ellos, con una cadena de ácidos grasos, de longitud variable (C7-C13) mediante un enlace amida. A diferencia de los CAPs, los CTOs se forman por la condensación mediante un enlace éster, del alcohol vainíllico, común a todos ellos, con cadenas de ácidos grasos similares a las que intervienen en la formación de CAPs. La longitud, la presencia de insaturaciones y/o ramificaciones en la cadena de ácidos grasos determinará el tipo de CTOs/CAPs biosintetizados y el grado de picor (Curry et al., 1999; Lang et al., 2006). La estructura química afecta a la intensidad del picor de cada compuesto, de este modo, los humanos somos capaces de percibir cada CAPs por separado; por ejemplo, la Cap y la dhCap son los más irritantes, la homodihidrocapsicina es muy irritante pero también penetrante y punzante y la ndhCap es la menos irritante (Bosland y Votava, 2012). A su vez, el picor de los CAPs es aproximadamente 1000 veces mayor que el de los CTOs (Tanaka et al., 2015).

Paralelamente a lo que ocurre con los SCs, las diferentes combinaciones de CAPs confieren unas características determinadas al picor de cada una de las variedades de pimiento. Por otra parte, la baja pungencia de los CTOs en comparación con los CAPs ofrece una alternativa al desarrollo de nuevas variedades de pimiento poco picantes para consumo en fresco con altos contenidos en compuestos bioactivos. Conocer en profundidad la biosíntesis y el control genético de todos estos compuestos es esencial para el desarrollo de marcadores moleculares útiles en la selección, mediante programas de mejora, de nuevas variedades adaptadas a las preferencias del consumidor.

\section{Biosíntesis de los compuestos relacionados con el picor}

La genética de la pungencia de la cebolla y del pimiento lleva siendo objeto de estudio desde hace más de 50 años; sin embargo, ni las rutas de biosíntesis de estos compuestos ni los genes implicados en ellas se conocen en su totalidad. A continuación se detallan los conocimientos actuales sobre la biosíntesis y el control genético de los SCs y los CTOs/CAPs.

\section{Ruta biosíntesis de los SCs}

Actualmente existen dos rutas propuestas para la biosíntesis de SCs, mientras una propone a los $\gamma$ GPs como intermediarios (Lancaster y Shaw, 1989), la otra sugiere la serina como precursor de la biosíntesis de SCs (Granroth, 1970). La ruta de biosíntesis mayormente aceptada plantea la biosíntesis de los SCS por medio de la S-alqu(en)ilación de la cisteína en glutatión, seguido de una transpeptidación para eliminar una glicina y formar $\gamma$ glutamil cisteína, su oxidación en sulfóxido de $\gamma$-glutamil cisteína y finalmente, la eliminación del grupo $\gamma$-glutamil para producir el SCs. Por otra parte, la ruta biosintética alternativa excluye el glutatión a favor de la alqu(en)ilación directa de la cisteína o de la tioalqu(en)ilación de la o-acetil serina seguida por la oxidación en sulfóxido. Sin embargo, 
la contribución de ambas rutas en la biosíntesis de SCs así como los genes implicados en cada una de ellas sigue aún sin conocerse en profundidad (Jones et al., 2004).

\section{Control genético de la pungencia} en cebolla (A. cepa)

La pungencia en cebolla es un carácter controlado por la acción de pocos genes (Owen, 1961). Sin embargo, el alto grado de alogamia, la depresión por consanguinidad y el carácter bienal que presentan las poblaciones de cebolla junto con el gran tamaño del genoma que incluye un elevado número de repeticiones, mucho mayor que el de otras especies de Allium, tomate o maíz, han dificultado la identificación de genes relacionados con la biosíntesis de los SCs así como de las rutas metabólicas en las que intervienen. Adicionalmente a la variabilidad genética, en numerosos estudios se ha documentado la influencia, sobre el contenido de SCs, de factores ambientales como el año de cultivo, la estación del año, la temperatura, el riego, la disponibilidad de azufre y nitrógeno en el medio de cultivo o el tiempo de almacenamiento (Simon, 1995; Randle et al., 1995; Mallor et al., 2011).

Mediante estudios de mapeo de QTLs (locus de un carácter cuantitativo, del inglés quantitative trait loci), se identificó, a partir del cruce entre los cultivares de cebolla 'BYG15-23' y 'AC43', un QTL localizado en el cromosoma 5 directamente correlacionado con el contenido total de materia seca y la pungencia (Galmarini et al., 2001). Dicho locus fue posteriormente confirmado en el cruce 'W202A' x 'Texas Grano 438' además de otro QTL mayor, directamente relacionado con el contenido en sólidos solubles y sin efectos pleiotrópicos, muy ligado a dos genes del cromosoma 3 codificantes para las enzimas ATP sulfurilasa (EC 2.7.7.4) y la sulfito reductasa (ferredoxina; EC 1.8.7.1), implicadas en las reacciones de metabolismo del azufre y su incorporación a la cisteína, respectivamente (McCallum et al., 2007).
La heredabilidad en sentido amplio del carácter pungente de la cebolla se estima entre $0,5-0,71$ y se correlaciona positivamente con el contenido en sólidos solubles y materia seca total (Mallor et al., 2011). Sin embargo, esta correlación se reduce significativamente tras las siguientes generaciones, obteniéndose en programas de mejora una buena respuesta a la selección de variedades dulces de cebolla, independientemente del contenido en sólidos solubles (Simon, 1995). La selección de cultivares con un amplio rango de adaptabilidad en cuanto a pungencia, capacidad de almacenamiento y cualidades para la industria alimentaria es un hito importante en los programas de mejora. En ese sentido, la determinación del contenido de SCS mediante técnicas analíticas precisas es fundamental, en mejora, para una buena selección de variedades de cebolla adaptadas a la demanda del consumidor.

\section{La biosíntesis de los capsinoides y capsicinoides (CTOs/CAPs)}

Como se ha comentado con anterioridad, el descubrimiento de los CTOs es mucho más reciente que los CAPs. Por ello, el conocimiento actual sobre la biosíntesis y el control genético de los CTOs, se basa en el conocimiento previamente establecido para los CAPs. La biosíntesis de los CTOs/CAPs se inicia a los 1520 días después de la antesis (dda) hasta alcanzar su máximo a los 40 dda y se acumulan principalmente en vesículas celulares de la placenta, el pericarpio y las semillas (Iwai et al., 1979; Lang et al., 2009; Tanaka et al., 2017). La base de la ruta de biosíntesis de los CAPs se estableció, por primera vez, a finales de los años 60 por Bennett y Kirby (1968) y por Leete y Louden (1968) a partir de la combinación de otras dos rutas de biosíntesis (Figura 2). Por un lado, la ruta de los fenilpropanoides genera el anillo aromático de CTOS/CAPs a partir de la fenilalanina, y por otro lado, la ruta de los áci- 


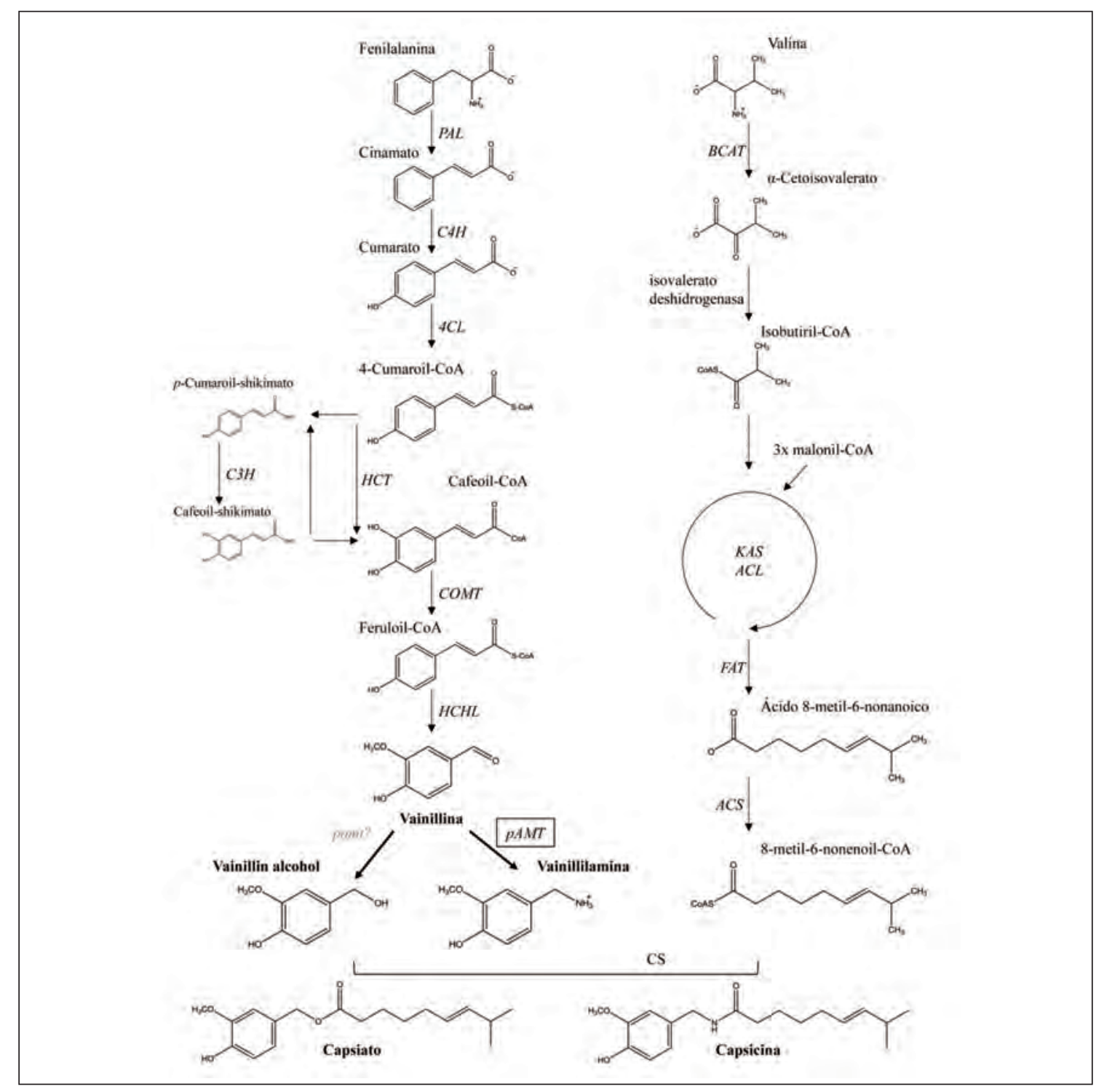

Figura 2. Ruta de biosíntesis de los capsicinoides. $P A L$, fenilalanina amonio liasa; $C 4 H$, cinamato 4-hidroxilasa; $4 C L$, 4-cumarato CoA ligasa; $H C T$, hidroxicinamoil transferasa; $C 3 H$, cumarato 3-hidroxilasa; COMT, ácido cafeico-O-metiltransferasa; $H C H L$, hidroxicinamoil-CoA hidratasa/liasa; pAMT, aminotransferasa putativa; $B C A T$, transferasa de aminoácidos de cadena ramificada; $K A S$, b-cetoacil-ACP sintasa; $A C L$, proteína transportadora de grupos acilos; FAT, acil-ACP tioesterasa; ACS, Acil-CoA sintetasa; CS, capsicina sintasa (modificada a partir de las rutas de biosíntesis propuestas por Stewart et al., 2005; Tanaka et al., 2010a,b y Aza-González et al., 2011).

Figure 2. Capsaicinoid biosynthesis pathway. $\mathrm{PAL}$, phenylalanine ammonia lyase; $\mathrm{C} 4 \mathrm{H}$, cinnamate 4hydroxylase; 4CL, 4-coumaroyl-CoA ligase; $\mathrm{HCT}$, hydroxycinnamoyl transferase; $\mathrm{C} 3 \mathrm{H}$, coumarate 3hydroxylase; COMT, caffeic acid O-methyltransferase; $\mathrm{HCHL}$, hydroxycinnamoyl-CoA hydratase/lyase; PAMT, putative aminotransferase; BCAT, branched-chain amino acid transferase; KAS, 3-ketoacyl-ACP synthase; ACL, acyl carrier protein; FAT, acil-ACP thioesterase; ACS, acyl-CoA synthetase; CS, capsaicin synthase (modified from Stewart et al., 2005; Tanaka et al., 2010a, b y Aza-González et al., 2011). 
dos grasos produce, a partir de los aminoácidos valina y leucina, las cadenas de ácidos grasos (Leete y Louden, 1968; Sutoh et al., 2006).

\section{El control genético del picante en Capsicum spp.}

El uso de radiotrazadores en la identificación de compuestos precursores e intermediarios y de técnicas de análisis de la expresión de genes como Northern Blot y RT-PCR han permitido establecer la participación de los genes fenilalanina amonio liasa $(P A L)$, cinamato 4-hidroxilasa (C4H o también conocido como $\mathrm{Ca} 4 \mathrm{H})$, cumarato 3-hidroxilasa $(\mathrm{C} 3 \mathrm{H})$, ácido cafeico-O-metiltransferasa (COMT o CCoAOMT), 4-cumarato CoA ligasa (4CL), hidroxicinamoil transferasa $(H C T)$, hidroxicinamoil-CoA hidratasa/liasa (HCHL) y aminotransferasa putativa ( $p A M T)$ en la ruta de los fenilpropanoides; así como, la de los genes transferasa de aminoácidos de cadena ramificada ( $B C A T)$, $\alpha$-cetoácido deshidrogenasa de cadena ramificada $(B C K D H), \beta$-cetoacilACP sintasa (Kas), proteína transportadora de grupos acilos $(A c l)$, acil-ACP tioesterasa (FatA) y acil-CoA sintetasa ( $A C S$ ) en la ruta de los ácidos grasos (Bennett y Kirby, 1968; Leete y Louden, 1968; Stewart et al., 2005; Aza-González et al., 2011). Basándose en el conocimiento previo, varios autores determinaron correlaciones entre los niveles de transcritos de los genes $P A L, C 4 H$, COMT y $P A M T$, expresados en la placenta, y el grado de picor de los frutos (Curry et al., 1999; Aza-González et al., 2011). Sin embargo, según el estudio recientemente publicado por Tanaka et al. (2017), basado en la técnica qRT-PCR, no existe relación directa entre el nivel de expresión de los genes PAL, C4H, 4CL, HTC, C3H, COMT, y la acumulación de CAPs; debido probablemente a la participación de dichos genes en otras rutas biosintéticas implicadas en la producción de múltiples metabolitos secundarios como flavonoides y ligninas (Tanaka et al., 2017). En este mismo estudio tampoco en- cuentran una correlación directa y consistente de los genes $B C K D H, A C L, F A T$ y $A C S$ con la acumulación de CAPs pero sí para los genes Pun1, pAMT, KAS y BCAT. Dado que la diferencia esencial entre CAPs y CTOs reside en el anillo aromático derivado de la vainillina, los genes clave para la biosíntesis de CAPs y/o CTOs estarán involucrados en la ruta de los fenilpropanoides, en concreto de los genes Pun1 y pAMT.

\section{El gen Pun1 determina la presencial ausencia del picor}

El gen dominante Pun1 (también conocido como locus $C$, lov, Catf-1) codifica para una enzima aciltransferasa (AT3), clave en la biosíntesis de CAPs y aparentemente, también de CTOs (Stewart et al., 2005; Lang et al., 2006; Han et al., 2013; Tanaka et al., 2017).

Por otro lado, la capsicina sintetasa (CS) es la última enzima de la ruta de biosíntesis de CAPs y es la responsable de la condensación del anillo aromático derivado de la vainillina con la cadena de ácidos grasos (Figura 2). Sin embargo, el gen que codifica para la CS así como la localización de la AT3 en la ruta de biosíntesis aún no se conocen (Han et al., 2013).

En consecuencia, todas las plantas de pimiento con frutos picantes presentan el genotipo Pun1Pun1 o Pun1pun1 (Han et al., 2013). En la actualidad se han encontrado cuatro mutaciones distintas para este gen y todas ellas dan lugar a plantas con frutos no picantes. Inicialmente se identificó el alelo pun $1{ }^{1}$, en los cultivares de C. annuum 'Jupiter', 'Maor' y 'Jalapeño Sweet 3575', el cual contiene una gran deleción de $2,5 \mathrm{~kb}$ a lo largo de la región promotora y el primer exón que impide la transcripción a ARNm (Stewart et al., 2005). Poco después se descubrió el alelo pun $1^{2}$ en el cultivar 'NMCA 30036' (C. chinense), cuya deleción de 4 pb en el primer exón, produce un cambio en el marco de lectura y por consiguiente, en la secuencia de 
aminoácidos dando como resultado el truncamiento de AT3 (Stewart et al., 2007) y el alelo pun $1^{3}$ descrito en el cultivar PI594141 (C. frutescens) el cual presenta una deleción de 70 aminoácidos en la región terminal de la AT3 (Stellari et al., 2010). Por último, el alelo pun $1^{4}$ se ha descrito recientemente en del cultivar japonés 'Nara Murasaki' (C. annuum) cuya mutación causada por la inserción de un nucleótido (A) en el segundo exón causa un cambio en el marco de lectura originando el truncamiento de la proteína (Kirii et al., 2017).

\section{El gen pAMT responsable de la biosíntesis de CAPs y CTOs}

El gen $p A M T$ codifica para la enzima pAMT, una aminotransferasa encargada de la conversión de vainillina en vainillilamina (Curry et al., 1999). En la actualidad se han descrito ocho alelos mutados para el gen $P A M T$ en un pequeño número de cultivares, produciéndose en todos ellos una mayor biosíntesis de CTOs en detrimento de CAPs. Por todo ello, pAMT ha sido propuesto como una pieza clave para la formación de CTOs durante la biosíntesis de CAPs. Los alelos pamt ${ }^{1}$ y pamt ${ }^{2}$ fueron descritos en $C$. annuum (Lang et al., 2009; Tanaka et al., 2010a). El alelo pamt ${ }^{1}$ del cultivar 'CH-19 Sweet' contiene una inserción (T) en la posición 1291, dicha mutación crea un nuevo codón de parada (TGA) y el alelo pamt ${ }^{2}$, identificado en el cultivar ' $\mathrm{Hi}$ mo', se caracteriza por la sustitución de una T por una $C$ en la posición 775 pb afectando al dominio PLP de la proteína, ambas mutaciones ocasionan la pérdida de función de la enzima pAMT. Paralelamente, se han descrito otros cinco alelos mutados en la especie C. chinense: el alelo pamt ${ }^{3}$ identificado en el cultivar 'Belize Sweet' contiene una inserción de 5 pb en el $8^{\circ}$ exón; el alelo pamt $t^{4}$ descrito en 'Zavory Hot' contiene una inserción de $2,3 \mathrm{~kb}$ en el $5^{\circ}$ intrón; el alelo pamt ${ }^{5}$ de
'Ají Dulce Strain2', 'No.2' y 'SNU11-001' se caracteriza por dos inserciones, una de $2,3 \mathrm{~kb}$ en $3^{\circ}$ intrón y otra de 8 pb en el $6^{\circ}$ exón (Tanaka et al., 2010b; Koeda et al., 2014; Jang et al., 2015); el alelo pamt ${ }^{6}$ con una inserción de $7 \mathrm{pb}$ en el $2^{\circ}$ exón, se encontró en el cultivar 'Pimento' (No.80) (Koeda et al., 2014) y el alelo pamt ${ }^{7}$, con una inserción de un fragmento de $2.8 \mathrm{~kb}$ en el $2^{\circ}$ exón en los cultivares 'LP6' y 'LP12' (Tanaka et al., 2015). Los fragmentos de 2,3 kb de los alelos pamt ${ }^{5}$ y pamt ${ }^{6}$ y $2,8 \mathrm{~kb}$ del alelo pamt $\mathrm{t}^{7}$ corresponden a la inserción del transposón Tcc (transposón de Capsicum chinense). Todas las inserciones en $C$. chinense producen un cambio en el marco de lectura dando lugar a una proteína truncada, incluso las inserciones en regiones intrónicas de los alelos pamt $t^{4}$ y pamt ${ }^{5}$ ya que la inserción del Tcc cambia el patrón de splicing del gen $P A M T$ por lo que parte del Tcc se transcribe (Tanaka et al., 2010b). Por último, el alelo pamt $^{8}$ descrito en el genotipo 'S3212' (C. frutescens) contiene una deleción de $12 \mathrm{pb}$ en el $7^{\circ}$ exón y un polimorfismo de un solo nucleótido (o SNP, del inglés Single Nucleotide Polymorphism) de una T por una C en la posición 1089 pb (Park et al., 2015).

No obstante, ninguna de las mutaciones descritas en el gen $p A M T$ ha sido capaz de bloquear completamente la ruta de biosíntesis de CAPs. Dado que en algunos cultivares muy picantes con $p A M T$ no mutado se han detectado trazas de CTOs y en todos los cultivares descritos con pamt mutado se sintetizan pequeñas cantidades de CAPs, otros genes, además de $P A M T$, podrían estar controlando la biosíntesis de los CTOs (Han et al., 2013; Tanaka et al., 2015). La identificación de genotipos en los que se biosinteticen únicamente CTOs es esencial para determinar el control genético de los CTOs, y en consecuencia, fundamental en programas de mejora para el desarrollo de variedades poco picantes con altos contenidos en compuestos bioactivos. 


\section{Evolución de las técnicas analíticas en la determinación de los SCs en cebolla y de los CTOs/CAPs en pimiento}

Durante décadas la determinación, directa o indirecta, de SCs en cebolla y de CTOs/CAPs en pimiento se ha llevado a cabo mediante métodos organolépticos, colorimétricos o de cromatografía en papel o en capa fina. Dada la poca precisión y especificidad de estos métodos, en la actualidad se han visto desplazados por técnicas analíticas más precisas y sensibles como la cromatografía de gases (CG) y la cromatografía líquida de (ultra)alta resolución (U)HPLC.

\section{Métodos analíticos en la determinación de SCs}

La determinación de SCs en cebolla se ha llevado a cabo tanto por métodos directos como indirectos. Aunque los métodos basados en el contenido de ácido pirúvico, ácidos sulfénicos o tiosulfinatos han sido ampliamente utilizados como medida indirecta del picor de la cebolla (Schwimmer y Mazelis, 1963; Rose et al., 2005; Randle et al., 1995; Kubec et al., 1999; Bacon et al., 1999; Mallor et al., 2011), en ocasiones es difícil establecer una relación significativa, y por lo general, se acaba subestimando el contenido real de SCs (Randle et al., 1995; Wang et al., 2007). Por ello, la determinación directa de los SCs ha evolucionado desde métodos cualitativos y semicuantitativos, mediante cromatografía en papel, analizadores de aminoácidos o cromatografía en capa fina (CCF) (Virtanen y Matikkala, 1959; Matikkala y Virtanen, 1967; Granroth, 1968; Lancaster y Kelly, 1983), hasta los más modernos y cuantitativos basados en técnicas más precisas y sensibles como la CG y la (U)HPLC.

Dada la extrema inestabilidad de los SCs, la mayoría de métodos analíticos publicados requieren de un paso de derivatización de la muestra previo al análisis mediante CG y (U)HPLC. Los diferentes agentes de derivatización junto con la versatilidad de ambas técnicas han permitido el desarrollo de numerosos métodos analíticos para la determinación de SCs en cebolla y otras especies de Allium, originando gran disparidad de resultados ( $\mathrm{Ta}$ bla 1). La cuantificación de SCs mediante HPLC acoplada a detectores de fluorescencia (FL) no logró una adecuada separación de los picos (Thomas y Parkin, 1994), por lo que los detectores de absorbancia cobraron especial interés en la determinación de SCs. La HPLC acoplada a detectores ultravioleta (UV) se ha utilizado tanto para la identificación (Auger et al., 1993) como para la cuantificación de SCs en cebolla. Mientras que Edwards et al. (1994) desarrollaron un método de HPLCUV, con gradiente y sin derivatización de la muestra, capaz de cuantificar PeSC, MeSC, PSC y por primera vez, ASC en cebolla, otros métodos de HPLC-UV menos sensibles no han sido capaces de detectar ASC y/o PSC (Randle et al. 1995; Yoo y Pike, 1998). Esta técnica ha sido utilizada como método de rutina en estudios de evolución del contenido de SCs en determinadas condiciones de almacenamiento o de abonado con azufre (Lancaster et al., 1998; Uddin y MacTavish, 2003). Sin embargo, ciertos métodos de CG con detección por espectrometría de masas (MS) mostraron mayor sensibilidad que los de HPLC-UV, especialmente en la determinación de SCs minoritarios (Tsuge et al., 2002; Wang et al., 2007), considerándose una buena alternativa a la HPLC. De hecho, Kubec et al. (2000) desarrollaron un método por CG-FID-MS capaz de cuantificar PeSC, MeSC, PSC, ASC y por primera vez, ESC en cebolla y otras 14 especies de Allium.

Otros detectores de absorbancia, utilizados en la determinación de SCs, acoplados a la HPLC son los de arreglo de diodos (DAD) y los de fotodiodos (PDA). A pesar de que la HPLCDAD se ha utilizado con fines tan diversos 


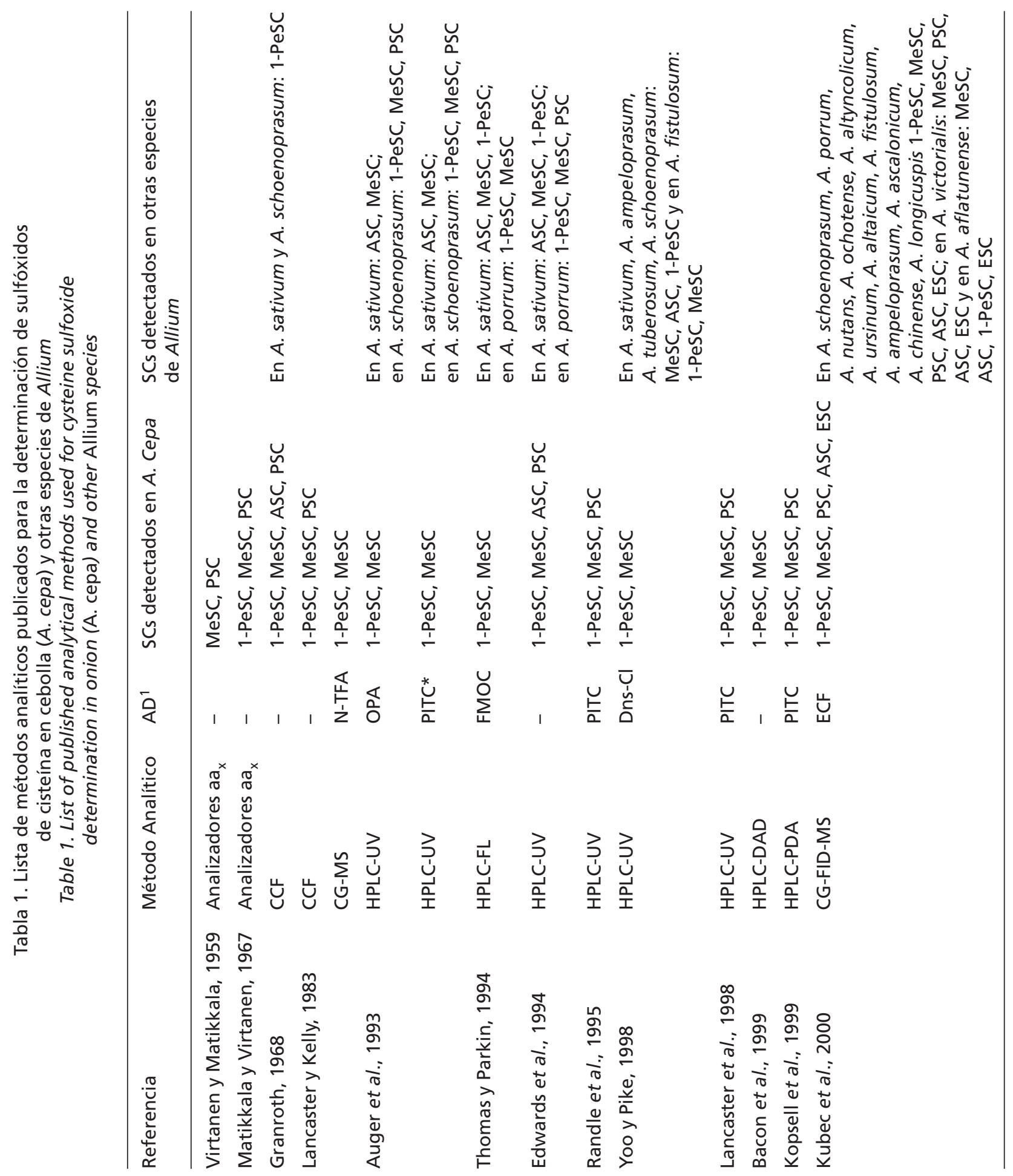




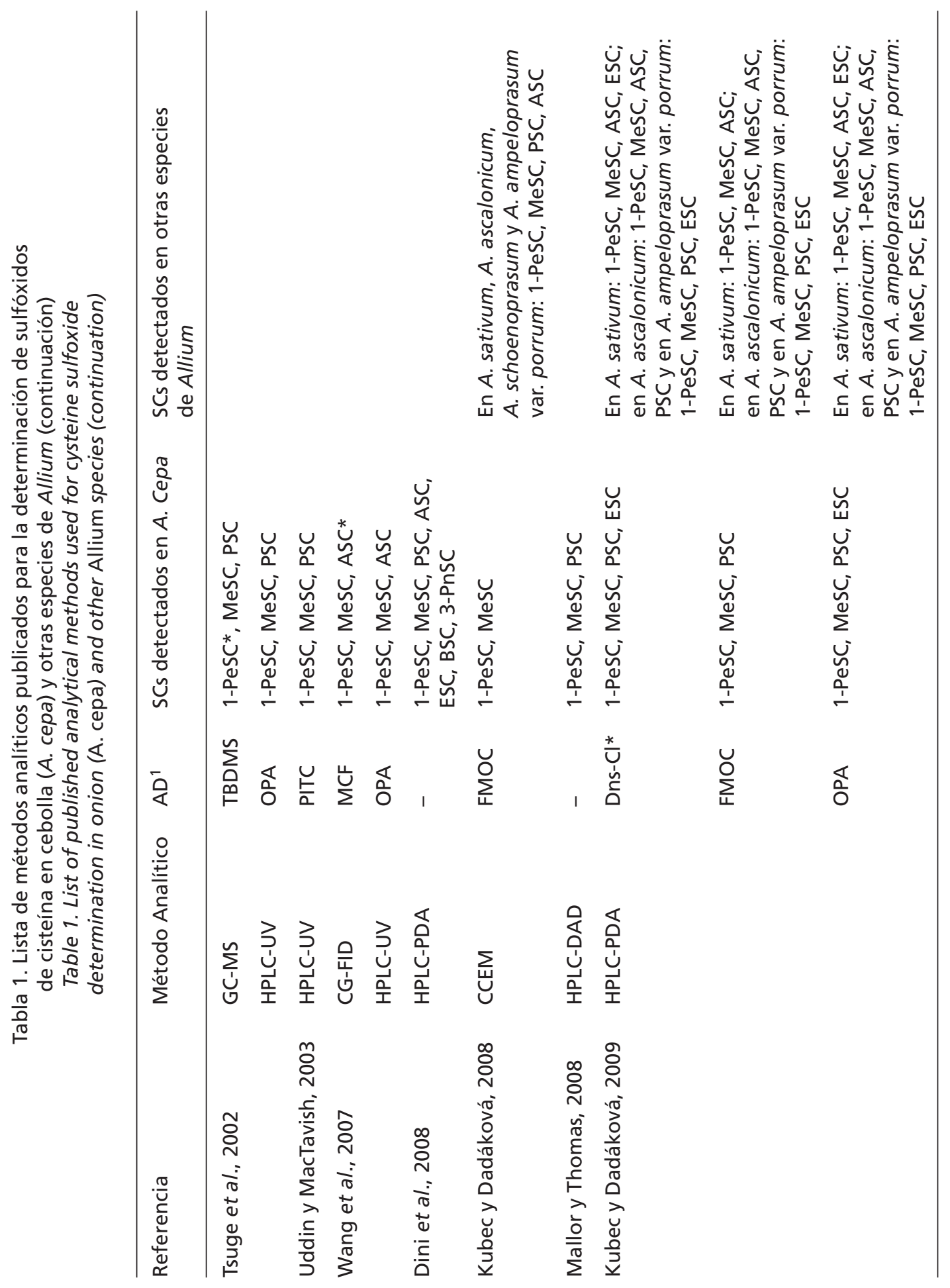



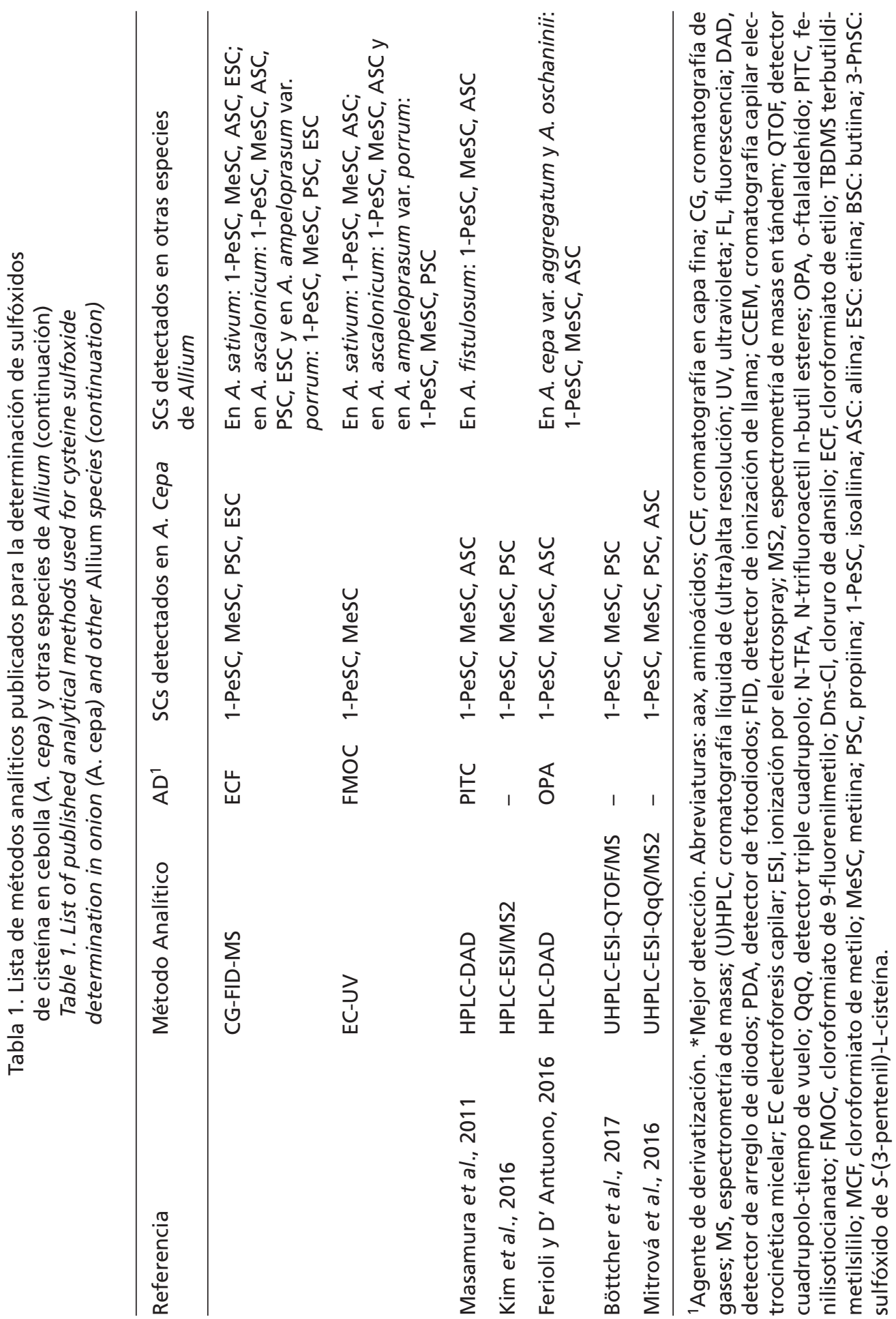
como el estudio de genes implicados en la ruta de biosíntesis de SCs en cebolletas de las especies $A$. fistulosum y $A$. cepa grupo aggregatum (Masamura et al., 2011), la caracterización de germoplasma en variedades locales de cebollas y chalotas de Italia y Ucrania (Ferioli y D'Antuono, 2016) y en la evaluación del contenido de SCs en función del genotipo, tejido y tiempo de almacenamiento (Bacon et al., 1999) o fotoperiodo (Mallor y Thomas, 2008), la sensibilidad de la técnica no permite la determinación de los minoritarios. Por otro lado, la mayor sensibilidad de la HPLC-PDA ha permitido la separación y cuantificación de SCs y algunos

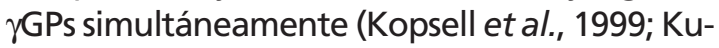
bec y Dadáková, 2009), así como la identificación de ESC, BSC y 3-PeSC además de los 4 principales, en semillas de $A$. cepa var. 'tropeana' (Dini et al., 2008), perfilándose como técnica prometedora en la determinación de SCs.

Simultáneamente, se desarrollaron otros métodos basados en la electroforesis capilar (EC) y cromatografía capilar electrocinética micelar, técnica híbrida entre la EC y la HPLC. Si bien la sensibilidad de estas técnicas es menor a la proporcionada por HPLC o CG, son una buena alternativa para análisis de rutina por su rapidez y bajo coste (Kubec y Dadáková, 2008 y 2009).

Por último, la (U)HPLC acoplada a detección por MS y MS/MS (en tándem) es la herramienta más potente que existe actualmente para la determinación de SCs en cebolla. La identificación inequívoca de los compuestos proporcionada por dicha técnica ha permitido su precisa cuantificación en estudios de caracterización de germoplasma (Mitrová et al., 2016), en el control de la evolución del contenido de SCs por efecto de la temperatura en diversos tratamientos culinarios (Kim et al., 2016) y en el análisis del perfil metabólico de la cebolla (Böttcher et al., 2017).

\section{Determinación de CAPs y CTOs}

Las primeras determinaciones del picor en pimiento se realizaron mediante el test organoléptico de Scoville (Scoville, 1912). En este test, un panel de catadores puntúa el nivel de picor, de una serie de diluciones de extractos de pimiento, en unidades Scoville (SHU, del inglés Scoville Heat Units). Aunque actualmente este método se sigue utilizando para evaluar el grado de picor, es un método subjetivo y poco preciso, viéndose desplazado por métodos analíticos de cromatografía por CG y (U)HPLC.

Si bien en la determinación de CAPs se han utilizado satisfactoriamente tanto la CG como la (U)HPLC, la inestabilidad de los CTOs ha condicionado su determinación exclusivamente por técnicas de (U)HPLC. La HPLCUV es la técnica más utilizada, por su rapidez y sencillez, en la determinación de los principales CAPs y CTOs en frutos de pimiento, sobre todo en estudios focalizados en el control genético del picor (Lang et al., 2009; Tanaka et al., 2010a,b; Tanaka et al., 2015; Tanaka et al., 2017). Simultáneamente, otros métodos de HPLC combinada con detectores (DAD/PDA) se han utilizado para la detección de los principales CTOs/CAPs en estudios de evaluación de la diversidad de metabolitos y caracterización de germoplasma (Singh et al., 2009; Wahyuni et al, 2011; Han et al., 2013; Coutinho et al., 2015; Jang et al., 2015). En comparación con los detectores de absorbancia, la detección por FL aporta un aumento de sensibilidad a la técnica de HPLC. La (U)HPLCFL ha permitido la determinación de Cap y dhCap en diferentes alimentos y salsas picantes (Barbero et al., 2016) así como en la identificación y cuantificación de CAPs minoritarios en estudios de maduración en frutos de la variedad 'Malagueta' para evaluar el contenido individual y total de CAPs (Fayos et al., 2017). 
Sin embargo, todas estas técnicas tienen limitaciones en cuanto a selectividad y sensibilidad, ya que tanto CTOs como CAPs emiten a la misma longitud de onda.

Por el contrario, la identificación inequívoca proporcionada por MS y MS/MS es fundamental para una determinación precisa de los compuestos minoritarios. La MS y MS/MS acoplada a la CG o a la (U)HPLC ha permitido la determinación de CAPs, mayoritarios y hasta 15 minoritarios en frutos y oleorresinas de pimiento, espráis de defensa, sangre y tejidos (Thompson et al., 2005; Garcés-Claver et al., 2006; Schweiggert et al., 2006). Además, la HPLC-MS/MS ha permitido el establecimiento de los patrones de fragmentación de CAPs (Reilly et al., 2001; Schweiggert et al., 2006) y de CTOs (Fayos et al., 2018).

\section{Perspectivas futuras de la investigación del carácter picante}

El carácter picante en Capsicum, considerado uno de los principales factores de calidad, incentiva el desarrollo de programas de mejora, enfocados a la obtención variedades de pimiento cada vez más picantes (Guzman y Bosland, 2017). No obstante, el picor del pimiento es un atributo no siempre deseable y apreciado por todos los consumidores. En consecuencia, un futuro objetivo de mejora deberá también enfocarse a la obtención de variedades poco picantes con altos contenidos en capsinoides y bajos o nulos contenidos de capsicinoides, adaptándose a la demanda de los mercados europeos (Silvar y GarcíaGonzález, 2017). Otras líneas de creciente interés son la mejora de la calidad en cebolla mediante la obtención de plantas doble haploides, utilizando ginogénesis in vitro, para la obtención de híbridos (Fayos et al., 2015) así como los programas de mejora específicos para la producción de cebollas tradicionales, como el tipo calçot (Simó et al., 2014), muy apreciada en algunas regiones de España.
No obstante, para alcanzar los objetivos de mejora de la calidad planteados a lo largo de esta revisión, es fundamental seguir investigando sobre la biosíntesis de capsinoides y capsicinoides en pimiento y de sulfóxidos de cisteína en cebolla. En este sentido, caben destacar los trabajos de Tanaka et al. (2017) y Han et al. (2013), relacionados con la identificación de genes responsables de la biosíntesis de capsinoides y capsicinoides, así como los llevados a cabo por Martínez-López et al. (2014), basados en la aplicación de herramientas genómicas para el desarrollo de transcriptomas en $C$. annuum. Con respecto a la ceboIla, hay que señalar la importante contribución de Block (2013) y Block et al. (1996) a la investigación de la biosíntesis de los sulfóxidos de cisteína en cebolla y otros Alliums.

\section{Agradecimientos}

Este trabajo ha sido financiado por los proyectos INIA-FEDER (RTA2011-00118-C02-01 y RTA2015-00042-C02-01) y el Gobierno de Aragón (Grupo de Investigación A16). O. Fayos es beneficiaria de una beca predoctoral FPI-INIA.

\section{Bibliografía}

Auger J, Mellouki F, Vannereau A, Boscher J, Cosson L, Mandon N (1993). Analysis of Allium sulfur amino acids by HPLC after derivatization. Chromatographia 36: 347-350.

Aza-González C, Núñez-Palenius HG, Ochoa-Alejo N (2011). Molecular biology of capsaicinoid biosynthesis in chili pepper (Capsicum spp.). Plant cell reports 30: 695-706.

Bacon JR, Moates GK, Ng A, Rhodes MJC, Smith AC, Waldron KW (1999). Quantitative analysis of flavour precursors and pyruvate levels in different tissues and cultivars of onion (Allium сера). Food Chemistry 64: 257-261. 
Barbero GF, Liazid A, Azaroual L, Palma M, Barroso CG (2016). Capsaicinoid contents in peppers and pepper-related spicy foods. International journal of food properties 19: 485-493.

Bennett DJ, Kirby GW (1968). Constitution and biosynthesis of capsaicin. Journal of the Chemical Society C: Organic 4: 442-446.

Block E, Bayer T, Naganathan S, Zhao SH (1996). Allium chemistry: synthesis and sigmatropic rearrangements of alk(en)yl 1-propenyl disulfide s-oxides from cut onion and garlic. Journal of the American Chemical Society 118: 2799-2810.

Block E (2013). Fifty years of smelling sulfur. Journal of Sulfur Chemistry 34: 158-207.

Bosland PW, Votava EJ (2012). Peppers: vegetable and spice Capsicums, 2nd Ed. CAB International, MA, USA. 230 pp.

Böttcher C, Krähmer A, Stürtz M, Widder S, Schulz H (2017). Comprehensive metabolite profiling of onion bulbs (Allium cepa) using liquid chromatography coupled with electrospray ionization quadrupole time-of-flight mass spectrometry. Metabolomics 13: 35.

Corzo-Martínez M, Corzo N, Villamiel M (2007). Biological properties of onions and garlic. Trends in Food Science \& Technology 18: 609-625.

Coutinho JP, Barbero GF, Fayos O, Garcés-Claver A, Godoy HT, Palma M, Barroso CG (2015). Use of multivariate statistical techniques to optimize the separation of 17 capsinoids by ultra performance liquid chromatography using different columns. Talanta 134: 256-263.

Curry J, Aluru M, Mendoza M, Nevarez J, Melendrez M, O’Connell MA (1999). Transcripts for possible capsaicinoid biosynthetic genes are differentially accumulated in pungent and nonpungent Capsicum spp. Plant Science 148: 47-57.

Dini I, Tenore GC, Dini A (2008). S-alkenyl cysteine sulfoxide and its antioxidant properties from Allium cepa var. tropeana (red onion) seeds. Journal of Natural Products 71: 2036-2037.

Edwards SJ, Musker D, Collin HA, Britton G (1994). The analysis of $S$ alk(en)yl L cysteine sulphoxides (flavour precursors) from species of Allium by high performance liquid chromatography. Phytochemical Analysis 5: 4-9.
Fayos O, Vallés MP, Garcés-Claver A, Mallor C, Castillo AM (2015). Doubled haploid production from Spanish onion (Allium cepa L.) germplasm: embryogenesis induction, plant regeneration and chromosome doubling. Front. Plant Sci. 6: 384.

Fayos O, Aguiar AC, Jiménez-Cantizano A, Ferreiro-González M, Garcés-Claver A, Martínez J, Mallor C, Ruíz-Rodríguez A, Palma M, Barroso CG, Barbero GF (2017). Ontogenetic variation of individual and total capsaicinoids in Malagueta peppers (Capsicum frutescens) during fruit maturation. Molecules 22: 736.

Fayos O, Barbero GF, Savirón M, Orduna J, Durán AG, Palma M, Molinillo JMG, Macías FA, Barroso CG, Mallor C, Garcés-Claver A (2018). Synthesis of ( \pm )-3,4-dimethoxybenzyl-4-methyloctanoate as a novel internal standard for capsinoid determination by HPLC-ESI-MS/MS(QTOF). Open Chemistry 16: 87-94.

Ferioli F, D'Antuono LF (2016). Evaluation of phenolics and cysteine sulfoxides in local onion and shallot germplasm from Italy and Ukraine. Genetic resources and crop evolution 63: 601-614.

Galmarini CR, Goldman IL, Havey MJ (2001). Genetic analyses of correlated solids, flavour, and health-enhancing traits in onion (Allium cepa L.). Molecular Genetics and Genomics 265: 543-551.

Garcés-Claver A, Arnedo-Andrés MS, Abadía J, Gil-Ortega R, Álvarez-Fernández A (2006). Determination of capsaicin and dihydrocapsaicin in Capsicum fruits by liquid chromatographyelectrospray/time-of-flight mass spectrometry. Journal of agricultural and food chemistry 54: 9303-9311.

Granroth B (1968). Separation of Allium sulfur amino acids and peptides by thin-layer electrophoresis and thin-layer chromatography. Acta Chemica Scandinavica 22: 3333-3335.

Granroth B (1970). Biosynthesis and decomposition of cysteine derivatives in onion and other Allium species. Annales Academiae Scientiarum Fennicae A 154: 71.

Guzman I, Bosland PW (2017). Sensory properties of chile pepper heat - and its importance to food quality and cultural preference. Appetite 117: 186-190. 
Han K, Jeong HJ, Sung J, Keum YS, Cho MC, Kim JH, Kwon JK, Kim BD, Kang BC (2013). Biosynthesis of capsinoid is controlled by the Pun 1 locus in pepper. Molecular breeding 31: 537-548.

Imai I, Tsuge N, Tomotake M, Nagatome Y, Sawada $H$, Nagata T, Kumagai $H$ (2002). An onion enzyme that makes the eyes water. Nature 419: 685.

Iwai K, Suzuki T, Fujiwake H (1979). Formation and accumulation of pungent principle of hot pepper fruits, capsaicin and its analogues, in Capsicum annuun var. annuun cv. Karayatsubusa at different growth stages after flowering. Agricultural and Biological Chemistry 43: 2493-2498.

Jang S, Han K, Jo YD, Jeong HJ, Siddique MI, Kang BC (2015). Substitution of a dysfunctional pAMT allele results in low-pungency but high levels of capsinoid in Capsicum chinense 'Habanero'. Plant Breed and Biotechnology 3: 119-128.

Jedelská J, Vogt A, Reinscheid UM, Keusgen M (2008). Isolation and identification of a red pigment from Allium subgenus Melanocrommyum. Journal of Agricultural and Food Chemistry 56: 1465-1470.

Jones MG, Hughes J, Tregova A, Milne J, Tomsett $A B$, Collin HA (2004). Biosynthesis of the flavour precursors of onion and garlic. Journal of Experimental Botany 55: 1903-1918.

Kim S, Lee S, Shin D, Yoo M (2016). Change in organosulfur compounds in onion (Allium cepa L.) during heat treatment. Food Science and Biotechnology 25: 115-119.

Kirii E, Goto T, Yoshida Y, Yasuba K, Tanaka Y (2017). Non-pungency in a japanese chili pepper landrace (Capsicum annuum) is caused by a novel loss-of-function Pun 1 allele. The Horticulture Journal 86: 61-69.

Kobata K, Todo T, Yazawa S, Iwai K, Watanabe T (1998). Novel capsaicinoid-like substances, capsiate and dihydrocapsiate, from the fruits of a nonpungent cultivar, $\mathrm{CH}-19$ Sweet, of pepper (Capsicum annuum L.). Journal of agricultural and food chemistry 46: 1695-1697.

Koeda S, Sato K, Tomi K, Tanaka Y, Takisawa R, Hosokawa M, Doi M, Nakazaki T, Kitajima A (2014). Analysis of non-pungency, aroma, and origin of a Capsicum chinense cultivar from a
Caribbean island. Journal of the Japanese Society for Horticultural Science 83: 244-251.

Kopsell DE, Randle WM, Eiteman MA (1999). Changes in the S-alk(en)yl cysteine sulfoxides and their biosynthetic intermediates during onion storage. Journal of the American Society for Horticultural Science 124: 177-183.

Kubec R, Svobodová M, Velíšek J (1999). Gas chromatographic determination of S-alk(en)ylcysteine sulfoxides. Journal of Chromatography A 862: 85-94.

Kubec R, Svobodová M, Velíšek J (2000). Distribution of $S$-alk(en)ylcysteine sulfoxides in some Allium species. Identification of a new flavor precursor: S-ethylcysteine sulfoxide (ethiin). Journal of Agricultural and Food Chemistry 48: 428-433.

Kubec R, Kim S, McKeon DM, Musah RA (2002). Isolation of $S$ - $n$-butylcysteine sulfoxide and six $n$ butyl-containing thiosulfinates from Allium siculum. Journal of Natural Products 65: 960-964.

Kubec R, Dadáková E (2008). Quantitative determination of S-alk(en)ylcysteine-S-oxides by micellar electrokinetic capillary chromatography. Journal of Chromatography A 1212: 154-157.

Kubec R, Dadáková E (2009). Chromatographic methods for determination of S-substituted cysteine derivatives-A comparative study. Journal of Chromatography A 1216: 6957-6963.

Kusterer J, Vogt A, Keusgen M (2010). Isolation and identification of a new cysteine sulfoxide and volatile sulfur compounds from Allium subgenus Melanocrommyum. Journal of Agricultural and Food Chemistry 58: 520-526.

Lancaster JE, Collin HA (1981). Presence of allinase in isolated vacuoles and of alkyl cysteine sulphoxides in the cytoplasm of bulbs of onion (Allium cepa). Plant Science Letters 22: 169-176.

Lancaster JE, Kelly E (1983). Quantitative analysis of the S-alk(en)-yl-L-cysteine sulfoxides in onion (Allium cepa L.). Journal of the Science of Food and Agriculture 34: 1229-1235.

Lancaster JE, Shaw ML (1989). $\gamma$-Glutamyl peptides in the biosynthesis of S-alk(en)yl-L-cysteine sulphoxides (flavour precursors) in Allium. Phytochemistry 28: 455-460. 
Lancaster JE, Shaw ML, Randle WM (1998). Differential hydrolysis of alk(en)yl cysteine sulphoxides by alliinase in onion macerates: flavour implications. Journal of the Science of Food and Agriculture 78: 367-372.

Lang $Y$, Yanagawa $S$, Sasanuma $T$, Sasakuma $T$ (2006). A gene encoding a putative acyl-transferase involved in pungency of Capsicum. Breeding Science 56: 55-62.

Lang $Y$, Kisaka H, Sugiyama R, Nomura K, Morita A, Watanabe T, Tanaka Y, Yazawa S, Miwa T (2009). Functional loss of pAMT results in biosynthesis of capsinoids, capsaicinoid analogs, in Capsicum annuum cv. CH-19 Sweet. The Plant Journal 59: 953-961.

Leete E, Louden MCL (1968). Biosynthesis of capsaicin and dihydrocapsaicin in Capsicum frutescens. Journal of the American Chemical Society 90: 6837-6841.

Luo XJ, Peng J, Li YJ (2011). Recent advances in the study on capsaicinoids and capsinoids. European journal of pharmacology 650: 1-7.

Mallor C, Thomas B (2008). Resource allocation and the origin of flavour precursors in onion bulbs. Journal of Horticultural Science \& Biotechnology 83: 191-198.

Mallor C, Balcells M, Mallor F, Sales E (2011). Genetic variation for bulb size, soluble solids content and pungency in the Spanish sweet onion variety Fuentes de Ebro. Response to selection for low pungency. Plant Breeding 130: 55-59.

Martínez-López LA., Ochoa-Alejo N, Martínez O (2014). Dynamics of the chili pepper transcriptome during fruit development. BMC Genomics 15: 143.

Masamura N, Yaguchi S, Ono Y, Nakajima T, Masuzaki SI, Imai S, Yamauchi N, Shigyo M (2011). Characterization of amino acid and S-alk (en) yl-L-cysteine sulfoxide production in Japanese bunching onion carrying an extra chromosome of shallot. Journal of the Japanese Society for Horticultural Science 80: 322-333.

Matikkala EJ, Virtanen AI (1967). On the quantitative determination of the amino acids and $\gamma$ glutamyl peptides of onion. Acta Chemica Scandinavica 21: 2891-2897.
McCallum J, Pither-Joyce M, Shaw M, Kenel F, Davis S, Butler R, Scheffer J, Jakse J, Havey MJ (2007). Genetic mapping of sulphur assimilation genes reveals a QTL for onion bulb pungency. Theoretical and Applied Genetics 114: 815-822.

Mitrová K, Hrbek V, Svoboda P, Hajšlová J, Ovesná J (2016). Antioxidant activity, S-alk(en)yl-I-cysteine sulfoxide and polyphenol content in onion (Allium cepa L.) cultivars are associated with their genetic background. Czech Journal of Food Sciences 34: 127-132.

Nelson EK (1919). The constitution of capsaicin, the pungent principle of Capsicum. Journal of the American Chemical Society 41: 1115-1121.

Owen EW (1961). The inheritance of dry matter in onion bulbs. M.S. Thesis. Univ. Idaho, Moscow, Idaho. 35 pp.

Park YJ, Nishikawa T, Minami M, Nemoto K, Iwasaki T, Matsushima K (2015). A low-pungency S3212 genotype of Capsicum frutescens caused by a mutation in the putative aminotransferase $(p-A M T)$ gene. Molecular genetics and genomics 290: 2217-2224.

Randle WM, Lancaster JE, Shaw ML, Sutton KH, Hay RL, Bussard ML (1995). Quantifying onion flavor compounds responding to sulfur fertilitysulfur increases levels of alk(en)yl cysteine sulfoxides and biosynthetic intermediates. Journal of the American Society for Horticultural Science 120: 1075-1081.

Reilly CA, Crouch DJ, Yost GS, Fatah AA (2001). Determination of capsaicin, dihydrocapsaicin, and nonivamide in self-defense weapons by liquid chromatography-mass spectrometry and liquid chromatography-tandem mass spectrometry. Journal of Chromatography A 912: 259-267.

Rose P, Whiteman M, Moore PK, Zhu YZ (2005). Bioactive $S$-alk (en) yl cysteine sulfoxide metabolites in the genus Allium: the chemistry of potential therapeutic agents. Natural product reports 22: 351-368.

Schweiggert U, Schieber A, Carle R (2006). Effects of blanching and storage on capsaicinoid stability and peroxidase activity of hot chili peppers (Capsicum frutescens L.). Innovative food science \& emerging technologies 7: 217-224. 
Schwimmer S, Mazelis M (1963). Characterization of Alliinase of Allium cepa (onion). Archives of Biochemistry and Biophysics 100: 66-73.

Scoville WL (1912). Note on Capsicums. Journal of Pharmaceutical Sciences 1: 453-454.

Silvar C, García-González CA (2017). Screening old peppers (Capsicum spp.) for disease resistance and pungency-related traits. Scientia Horticulturae 218: 249-257.

Simó J, Pascual L, Cañizares J, Casanas F (2014). Spanish onion landraces (Allium cepa L.) as sources of germplasm for breeding calçots: a morphological and molecular survey. Euphytica 195:287-300.

Simon PW (1995). Genetic analysis of pungency and soluble solids in long-storage onions. Euphytica 82:1-8.

Singh S, Jarret R, Russo V, Majetich G, Shimkus J, Bushway R, Perkins B (2009). Determination of capsinoids by HPLC-DAD in Capsicum species. Journal of agricultural and food chemistry 57 : 3452-3457.

Stellari GM, Mazourek M, Jahn MM (2010). Contrasting modes for loss of pungency between cultivated and wild species of Capsicum. Heredity 104: 460-471.

Stewart JC, Kang BC, Liu K, Mazourek M, Moore SL, Yoo EY, Kim BD, Paran I, Jahn MM (2005). The Pun1 gene for pungency in pepper encodes a putative acyltransferase. The Plant Journal 42: 675-688.

Stewart JC, Mazourek M, Stellari GM, O'connell M, Jahn M (2007). Genetic control of pungency in C. chinense via the Pun1 locus. Journal of Experimental Botany 58: 979-991.

Stoll A, Seebeck E (1947). Alliin, the pure mother substance of garlic oil. Experientia 3: 114-115.

Sutoh K, Kobata K, Yazawa S, Watanabe T (2006). Capsinoid is biosynthesized from phenylalanine and valine in a non-pungent pepper, Capsicum annuum L. cv. CH-19 sweet. Bioscience, biotechnology, and biochemistry 70: 1513-1516.

Tanaka Y, Hosokawa M, Miwa T, Watanabe T, Yazawa S (2010a). Newly mutated putative-ami- notransferase in nonpungent pepper (Capsicum annuum) results in biosynthesis of capsinoids, capsaicinoid analogues. Journal of agricultural and food chemistry 58: 1761-1767.

Tanaka Y, Hosokawa M, Miwa T, Watanabe T, Yazawa S (2010b). Novel loss-of-function putative aminotransferase alleles cause biosynthesis of capsinoids, nonpungent capsaicinoid analogues, in mildly pungent chili peppers (Capsicum chinense). Journal of agricultural and food chemistry 58: 11762-11767.

Tanaka Y, Sonoyama T, Muraga Y, Koeda S, Goto T, Yoshida Y, Yasuba K (2015). Multiple loss-of-function putative aminotransferase alleles contribute to low pungency and capsinoid biosynthesis in Capsicum chinense. Molecular Breeding 35: 142.

Tanaka Y, Nakashima F, Kirii E, Goto T, Yoshida Y, Yasuba KI (2017). Difference in capsaicinoid biosynthesis gene expression in the pericarp reveals elevation of capsaicinoid contents in chili peppers (Capsicum chinense). Plant cell reports 36: 267-279.

Thomas DJ, Parkin KL (1994). Quantification of alk(en)yl-L-cysteine sulfoxides and related amino acids in Alliums by high-performance liquid chromatography. Journal of Agricultural and Food Chemistry 42: 1632-1638.

Thompson RQ, Phinney KW, Welch MJ, White E (2005). Quantitative determination of capsaicinoids by liquid chromatography-electrospray mass spectrometry. Analytical and bioanalytical chemistry 381: 1441-1451.

Tsuge K, Kataoka M, Seto Y (2002). Determination of S-methyl-, S-propyl-, and S-propenyl-L-cysteine sulfoxides by gas chromatography-mass spectrometry after tert-butyldimethylsilylation. Journal of Agricultural and Food Chemistry 50: 4445-4451.

Uddin MM, MacTavish HS (2003). Controlled atmosphere and regular storage-induced changes in S-alk(en)yl-l-cysteine sulfoxides and alliinase activity in onion bulbs (Allium cepa L. cv. Hysam). Postharvest Biology and technology 28: 239-245.

Virtanen Al, Matikkala EJ (1959). The isolation of $S$-methyl-L-cysteine sulphoxide and $S$ - $n$-propyl- 
L-cysteine sulphoxide from onion (Allium cepa) and the antibiotic activity of crushed onion. Acta chemica scandinavica 13(9): 1898-1900.

Wahyuni Y, Ballester AR, Sudarmonowati E, Bino RJ, Bovy AG (2011). Metabolite biodiversity in pepper (Capsicum) fruits of thirty-two diverse accessions: variation in health-related compounds and implications for breeding. Phytochemistry 72: 1358-1370.

Wang H, Li J, Wang Z, Zhang X, Ni Y (2007). Modified method for rapid quantitation of $S$ Alk(en)yl-L-cysteine sulfoxide in yellow onions (Allium cepa L.). Journal of Agricultural and Food Chemistry 55: 5429-5435.
Yazawa S, Suetom N, Okamoto K, Namiki T (1989). Content of capsaicinoids and capsaicinoid-like substances in fruit of pepper (Capsicum annuum L.) hybrids made with ' $\mathrm{CH}-19$ Sweet' as a parent. Journal of the Japanese society for horticultural science 58: 601-607.

Yoo KS, Pike LM (1998). Determination of flavor precursor compound S-alk(en)yl-L-cysteine sulfoxides by an HPLC method and their distribution in Allium species. Scientia Horticulturae 75: 1-10.

(Aceptado para publicación el 1 de diciembre de 2017) 